University of Wollongong

Research Online

Faculty of Engineering and Information

Faculty of Engineering and Information

Sciences - Papers: Part A

Sciences

$1-1-2014$

\title{
Voltage unbalance emission allocation using constrained bus voltage method in radial distribution networks
}

\author{
Devinda Perera \\ University of Wollongong, bmdp065@uowmail.edu.au \\ Philip Ciufo \\ University of Wollongong, ciufo@uow.edu.au \\ Sarath Perera \\ University of Wollongong, sarath@uow.edu.au \\ Lasantha Meegahapola \\ University of Wollongong, lasantha.meegahapola@rmit.edu.au
}

Follow this and additional works at: https://ro.uow.edu.au/eispapers

Part of the Engineering Commons, and the Science and Technology Studies Commons

Research Online is the open access institutional repository for the University of Wollongong. For further information contact the UOW Library: research-pubs@uow.edu.au 


\title{
Voltage unbalance emission allocation using constrained bus voltage method in radial distribution networks
}

\author{
Abstract \\ The International Electrotechnical Committee Technical Report IEC 61000-3-13 is focused on the \\ coordination of voltage unbalance $(\mathrm{VU})$ in power systems by prescribing a methodology to determine \\ individual VU emission allocation limits to installations. This paper provides an alternative VU emission \\ allocation process to that of the IEC Technical Report, which is based on the concept of constrained bus \\ voltage (CBV) method. The proposed methodology can be used in relation to radial distribution networks \\ with symmetrical distribution lines. Several application examples of the proposed methodology are \\ presented. It is shown that the proposed methodology is superior in comparison to the VU allocation \\ methodology presented in IEC technical reports, as it enables the network VU absorption capacity to be \\ fully utilised.

\section{Keywords} \\ unbalance, networks, voltage, distribution, radial, method, bus, constrained, allocation, emission \\ Disciplines \\ Engineering | Science and Technology Studies

\section{Publication Details} \\ D. Perera, P. Ciufo, S. Perera \& L. Meegahapola, "Voltage unbalance emission allocation using constrained \\ bus voltage method in radial distribution networks," in 16th IEEE International Conference on Harmonics \\ and Quality of Power (ICHQP), 2014, pp. 273-277.
}




\title{
Voltage Unbalance Emission Allocation Using Constrained Bus Voltage Method in Radial Distribution Networks
}

\author{
Devinda Perera, Phil Ciufo*, Sarath Perera and Lasantha Meegahapola Australian Power Quality and Reliability \\ Centre, School of Electrical, Computer and Telecommunications Engineering, University of Wollongong,
}

Australia.ciufo@uow.edu.au*

\begin{abstract}
The International Electrotechnical Committee Technical Report IEC 61000-3-13 is focused on the coordination of voltage unbalance ( $\mathrm{VU})$ in power systems by prescribing a methodology to determine individual $\mathrm{VU}$ emission allocation limits to installations. This paper provides an alternative VU emission allocation process to that of the IEC Technical Report, which is based on the concept of constrained bus voltage (CBV) method. The proposed methodology can be used in relation to radial distribution networks with symmetrical distribution lines. Several application examples of the proposed methodology are presented. It is shown that the proposed methodology is superior in comparison to the $\mathrm{VU}$ allocation methodology presented in IEC technical reports, as it enables the network VU absorption capacity to be fully utilised.
\end{abstract}

Index Terms - constrained bus voltage method, emission allocation, radial power systems, three-phase induction motors, voltage unbalance (VU), VU attenuation, VU transfer coefficient

\section{INTRODUCTION}

$\mathbf{T}$ HE International Electromechanical Committee (IEC) has published a series of technical reports providing guiding principles to system operators, on determining the requirements for the connection of disturbing installations such that adequate power quality (PQ) to all connected customers is ensured. Development of methodologies for calculating the PQ disturbance emission allocation limits for individual installations is an inherent part of the aforementioned process. Such methodologies should ensure that the network PQ disturbance absorption capacity is utilised as much as possible, while maintaining the PQ disturbance levels at any part of the network within the reference values known as compatibility levels [1].

With regard to voltage unbalance (VU), the IEC has recently published the Technical Report IEC TR 61000-3-13 [2]. This Technical Report is mainly focused on VU emission allocation for unbalanced installations connected to MV, HV and EHV networks. The concept of a $k_{u E}$ factor is introduced in this Technical Report to account for VU which arises due to the asymmetry of the supply networks. Similar to its counterpart, IEC 61000-3-6 [3] for harmonics and IEC 610003-7 [4] for flicker, IEC 61000-3-13 provides a three-stage emission allocation process. Under stage one, installations which have low short-circuit ratios at the point of common coupling are exempted from emission limits and are allowed to connect without any detailed analysis. For larger installations (depending on their MVA capacity), the stage two emission allocation process is applicable, in which emission limits are derived based on the principle of apportioning the available

NOTICE: this is the authors' version of a work that was accepted for publication in the ICHQP proceedings. Changes resulting from the publishing process, such as peer review, editing, corrections, structural formatting, and other quality control mechanisms may not be reflected in this document. Changes may have been made to this work since it was submitted for publication. A definitive version was subsequently published in the Proceedings of the 16th IEEE International Conference on Harmonics and Quality of Power, the 16th IEEE International Conference on Harm
May 2014, DOI:10.1109/ICHQP.2014.6842913 distortion absorption capacity of the network with respect to the installation MVA capacity. Installations which do not fall into stage two category compliance limits, additional emission limits can be provided on temporary basis under stage three, which requires detailed investigation of the network.

In addition to the VU emission allocation methodology given in the IEC Technical Report, national level guidelines are available in some countries for coordination of VU. For instance, the Technical Report, "Technical Rules for the Assessment of Network Disturbances" is used in Austria, Switzerland, Czech Republic and Germany, in which a fixed VU emission allocation limit is prescribed for all installations irrespective of their MVA capacities and point of connection [5]. The constrained bus voltage method (CBV) has been proposed in [6] as an alternative methodology for harmonic and flicker emission allocation, in which emission levels at network busbars are explicitly forced to be set at reference levels when all installations are injecting their limits derived under the CBV methodology. Application of the CBV method for $\mathrm{VU}$ emission allocation in $\mathrm{HV}$ meshed networks is carried out in [1]. However, due to the meshed structure of the networks, considerable effort is required in deriving the emission allocation limits under the CBV method.

The main objective of the current research is to propose a simplified VU emission allocation methodology based on the concepts of CBV specifically for distribution networks with short MV distribution lines and completely transposed distribution lines where line impedance asymmetries are negligible [2]. The paper is organised as follows. The background details in relation to propagation of VU and the summation of VU from multiple unbalanced sources together with a general expression for estimating the VU at any location in a radial feeder is given in Section II. Section III presents the revised VU allocation methodology based on the concepts of CBV. Several case studies which illustrate the application of the proposed methodology is also given in Section III. A study which investigates the impact of mains connected three-phase induction motors on the VU emission allocation process is presented in Section IV. Conclusions are given in Section V.

\section{Estimation of Voltage Unbalance at VARious} LOCATIONS OF A RADIAL FEEDER

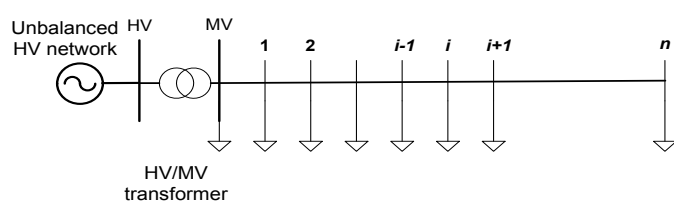

Fig. 1. Radial distribution network with multiple installations

In order to establish a general expression for voltage unbalance factor (VUF) at various locations along a feeder 


$$
\begin{gathered}
\left(V U F_{i \text { :total }}\right)^{\alpha}=\left(V U F_{\mathrm{HV}}\right)^{\alpha}+\left(E_{V U F: \mathrm{MV}}\right)^{\alpha}+\sum_{m=1}^{i-1}\left[E_{V U F: m}\right]^{\alpha}+E_{V U F: i}^{\alpha}+\sum_{m=i+1}^{n}\left[\frac{S_{s c: m}}{S_{s c: i}} E_{V U F: m}\right]^{\alpha} \\
\left(V U F_{\mathrm{MV} \text { total }}\right)^{\alpha}=\left(V U F_{\mathrm{HV}}\right)^{\alpha}+\left(E_{V U F: \mathrm{MV}}\right)^{\alpha}+\sum_{m=1}^{n}\left[\frac{S_{s c: m}}{S_{s c: \mathrm{MV}}} E_{V U F: m}\right]^{\alpha} \\
\left(V U F_{\mathrm{n}: \text { total }}\right)^{\alpha}=\left(V U F_{\mathrm{HV}}\right)^{\alpha}+\left(E_{V U F: \mathrm{MV}}\right)^{\alpha}+\sum_{m=1}^{n}\left[E_{V U F: m}\right]^{\alpha}
\end{gathered}
$$

where multiple unbalanced installations are connected, consider the radial distribution network given in Fig. 1. Multiple unbalanced installations are connected to the MV busbar and intermediate busbars 1 to $n$. The distribution line sections are assumed to be symmetrical. Considering one installation at a time, VU attenuation when it propagates to upstream from the point of connection (PCC) of the installation under consideration, can be expressed in terms of VU transfer coefficient (i.e. the ratio of VUF at the upstream point to VUF at the PCC of the installation). Referring to Appendix A, the VU transfer coefficient from downstream to upstream of the network can be approximated by the ratio of fault levels of two locations. The VU transfer coefficient from the PCC of the installation to a downstream point of the network will be equal to unity as there are no further installations connected at downstream. Thus, assuming that only the installation connected to $i^{\text {th }}$ busbar is operating, the VU transfer coefficient from $i^{\text {th }}$ busbar to the MV busbar $\left(T_{u: i-\mathrm{MV}}\right)$ and the VU transfer coefficient from $i^{\text {th }}$ to the $n^{\text {th }}$ busbar $\left(T_{u: i-n}\right)$ can be given by (1) and (2) respectively,

$$
\begin{gathered}
T_{u: i-\mathrm{MV}} \approx \frac{S_{s c: i}}{S_{s c: \mathrm{MV}}} \\
T_{u: i-n}=1
\end{gathered}
$$

where;

$S_{s c: i}$ is the short-circuit level at the intermediate busbar $i$

$S_{s c: \mathrm{MV}}$ is the short-circuit level at the MV busbar

When multiple unbalanced installations are operating simultaneously, the VU emission of each unbalanced installation can be influenced by the other unbalanced installations connected to adjacent busbars. Hence, development of a deterministic approach to estimate the net VU at each busbar would be difficult [10]. A general summation law based on a statistical approach has been proposed in [2] as a means for calculation of disturbances caused by multiple sources.

Following the aforementioned principles in relation to $\mathrm{VU}$ propagation and summation law proposed in [2], a general expression for VUF at the $i^{\text {th }}$ busbar can be formulated. Referring to (3) and Fig. 1, the total VUF at the $i^{\text {th }}$ busbar results from the VU that propagates from the upstream HV network $\left(V U F_{\mathrm{HV}}\right)$, VU that propagates to $i^{\text {th }}$ busbar from MV busbar due to the VU emission from the installation connected to the MV busbar $\left(E_{V U F: M V}\right)$, VU that propagates to the $i^{\text {th }}$ busbar from all busbars which are upstream to $i^{\text {th }}$ busbar due to VU emission from unbalanced installations connected to those busbars $\left(\sum_{m=1-1}^{i-1}\left[E_{V U F: m}\right]\right)$, VU emission from the installation connected at the $i^{\text {th }}$ busbar
$\left(E_{V U F: i}\right)$ and $\mathrm{VU}$ that propagates to $i^{\text {th }}$ busbar from all other busbars located downstream of $i^{\text {th }}$ busbar due to VU emission from unbalanced installations connected to those busbars $\left(\sum_{m=i+1}^{n}\left[\frac{S_{s c: m}}{S_{s c: i}} E_{V U F: m}\right]\right)$. Hence, using the general summation law, the total VUF at the $i^{\text {th }}$ busbar $\left(V U F_{i \text { :total }}\right)$ can be written as (3). Similarly, the VUF at the MV busbar $\left(V U F_{\mathrm{MV} \text { :total }}\right)$ and VUF at the $n^{\text {th }}$ busbar $\left(V U F_{n: \text { total }}\right)$ can be given by (4) and (5) respectively.

In (3) to (5);

$V U F_{\mathrm{MV}}$ :total is the magnitude of resultant VUF at MV busbar, $V U F_{\mathrm{HV}}$ is the magnitude of VUF transferred from the upstream network,

$E_{V U F: \mathrm{MV}}$ is the magnitude of VU emission from the unbalanced installations directly connected to the MV busbar,

$E_{V U F: m}$ is the magnitude of VU emission from installations connected downstream to the MV busbar, and $m=$ $1,2,3, \ldots, i-1, i+1, \ldots, n$,

$S_{s c: m}$ is the short-circuit level at any intermediate busbar $m$, $S_{s c: \mathrm{MV}}$ is the short-circuit level at the MV busbar,

$\alpha$ is the general summation component for $\mathrm{VU}$ and is equal to 1.4 .

\section{Voltage Unbalance Emission Allocation USing CBV METHODOLOGY FOR RADIAL DISTRIBUTION NETWORKS}

\section{A. General Principles}

In the VU coordination process, the compatibility between system VU levels and equipment immunity levels is ensured by providing reference values known as compatibility level values [2]. These values are determined based on the $95 \%$ probability of VU in the entire power system. The compatibility value of VU at the public LV network is given in [7]. The system operators should ensure that VU levels at any part of the network do not exceed the compatibility level.

Based on the compatibility level value, planning level values are defined for different voltage levels. Planning level values are considered as internal quality objectives of respective network operators and depend on the structure of the network. Indicative values for planning levels for different voltage levels are given in [2]. Planning level values should always be equal to or lower than the compatibility level values.

Assume that the VU emission allocation limit of an unbalanced installation connected to the distribution network shown in Fig. 1 is related to the agreed power of the installations as given by (6),

$$
E_{V U F: i}=k \cdot \sqrt[\alpha]{S_{i}}
$$


where $E_{V U F: i}$ is the emission allocation limit for the installation that is connected to the $i^{\text {th }}$ busbar (voltage unbalance factor), $S_{i}$ is the agreed power of the installation in per-unit, $\alpha$ is the general summation component and $k$ is an allocation constant, which is dependent on the distribution network under consideration.

When the MVA capacity of each installation and the shortcircuit level of each busbar is known in advance and by substituting the VU emission in (3)-(5) by the VU emission for each installation (given by (6)) the net VUF at each busbar can be estimated using (3)-(6) as a function of allocation constant $k$. Considering that the VUF at any busbar should not exceed the set planning level for the distribution network, a suitable value for $k$ can be determined. For example, when the value of $k$ is increased from zero up to a certain value in (3)-(5), the VUF at one of the busbar (called as the critical busbar) will reach the set planning level. The value of $k$ in which the critical busbar reach its planning level is then selected as the allocation constant. Thereafter, the emission allocation limits for all installations can be calculated using (6). The acceptable negative-sequence current allocation limit $\left(E_{I_{2}: i}\right)$ for the installation under consideration can be determined by (7) $[2]$,

$$
E_{I_{2}: i}=\frac{E_{V U F: i}}{Z_{22: i}}
$$

where $Z_{22: i}$ is the negative-sequence impedance at the $i^{\text {th }}$ busbar. In general, $Z_{22: i}$ can be assumed to be equal to the positive-sequence impedance at the $i^{\text {th }}$ busbar $Z_{11: i}$.

\section{B. Application Example of the Proposed Methodology}

1) Case I: In order to demonstrate the application of the proposed methodology in Section III-A, consider the radial distribution network given in Fig. 2. The radial distribution network consists of six unbalanced installations with MVA capacities as given in Table I, connected via balanced distribution lines to the HV/MV transformer. The impedance data of the distribution lines and of the HV/MV transformer are given in Appendix B. The calculation procedure of emission limits for each unbalanced installation, using the proposed methodology is described in the following steps.

An HV planning level ( $\left.L_{u \mathrm{HV}}\right)$ of $1.35 \%$, MV planing level $\left(L_{u \mathrm{MV}}\right)$ of $1.75 \%$ and a $\mathrm{HV}$ to MV transfer coefficient $\left(T_{u H M}\right)$ of unity are assumed for the network [2] $]^{1}$. The VU that propagates from the HV network to the MV network can be calculated as $V U F_{\mathrm{HV}}=T_{u H M} \cdot L_{u \mathrm{HV}}$. Each installation is given a VU emission allocation defined according to (6) Employing (6) and (3), the VUF at the PCC of each installation can be calculated for various values of $k$. The resultant VUF at each busbar when $k=0.0061$ for base MVA of 10 MVA is given in Table I.

According to Table I, the resultant VUF at the PCC of the installation L5 (Bus ID E) is observed reach the planning level of $1.75 \%$. Hence, the allocation constant can be selected as 0.0061 for the network. The resulting VU emission limits are for each installation are given in Table I column 4.

\footnotetext{
${ }^{1}$ The values for $\mathrm{HV}$ and MV planning levels are selected based on the indicative values given in IEC TR 61000-3-13 [2] for HV and MV networks. The HV to MV transfer coefficient is selected as unity as there is no induction motor loads connected to the MV network.
}

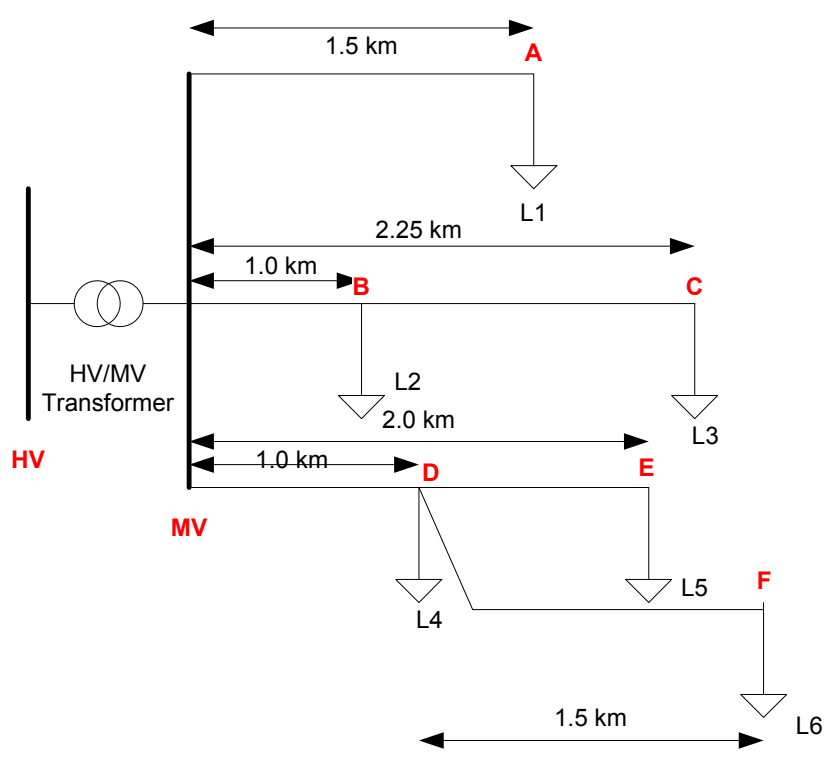

Fig. 2. Test MV distribution network

TABLE I

EMISSION ALLOCATION LIMIT FOR EACH INSTALLATION IN CASE I $\left(k=0.0061, S_{\text {base }}=10 \mathrm{MVA}\right)$

\begin{tabular}{|c|c|c|c|}
\hline Bus ID & $\begin{array}{c}\text { Installation capacity } \\
\text { connected to the bus }\end{array}$ & $\begin{array}{c}\text { Total VUF at } \\
\text { the busbar (\%) }\end{array}$ & $\begin{array}{c}\text { Allocated VUF to } \\
\text { the installation (\%) }\end{array}$ \\
\hline MV & - & 1.6091 & - \\
A & $2.0 \mathrm{MVA}$ & 1.6424 & 0.1932 \\
B & $5.0 \mathrm{MVA}$ & 1.7028 & 0.3717 \\
$\mathbf{C}$ & $3.5 \mathrm{MVA}$ & 1.7437 & 0.2881 \\
$\mathbf{D}$ & $2.5 \mathrm{MVA}$ & 1.6997 & 0.2266 \\
$\mathbf{E}$ & $5.0 \mathrm{MVA}$ & 1.7500 & 0.3717 \\
$\mathbf{F}$ & $2.0 \mathrm{MVA}$ & 1.7259 & 0.1932 \\
\hline
\end{tabular}

TABLE II

EMISSION ALLOCATION LIMITS FOR EACH INSTALLATION IN CASE II $\left(k=0.0087, S_{\text {base }}=10 \mathrm{MVA}\right)$

\begin{tabular}{|c|c|c|c|c|}
\hline $\begin{array}{c}\text { Bus } \\
\text { ID }\end{array}$ & $U_{f}$ & $\begin{array}{c}\text { Installation capacity } \\
\text { connected to the bus }\end{array}$ & $\begin{array}{c}\text { Total VUF at } \\
\text { the busbar }(\%)\end{array}$ & $\begin{array}{c}\text { Allocated VUF to } \\
\text { the installation }(\%)\end{array}$ \\
\hline $\mathbf{M V}$ & - & - & 1.6091 & - \\
$\mathbf{A}$ & 0.5 & $2.0 \mathrm{MVA}$ & 1.6474 & 0.1689 \\
$\mathbf{B}$ & 1.0 & $5.0 \mathrm{MVA}$ & 1.7291 & 0.5330 \\
$\mathbf{C}$ & 0.0 & $3.5 \mathrm{MVA}$ & 1.7291 & 0 \\
$\mathbf{D}$ & 0.5 & $2.5 \mathrm{MVA}$ & 1.7067 & 0.1981 \\
$\mathbf{E}$ & 0.5 & 5.0 MVA & 1.7484 & 0.3250 \\
$\mathbf{F}$ & 1.0 & $2.0 \mathrm{MVA}$ & 1.7500 & 0.2771 \\
\hline
\end{tabular}

2) Case II: In certain situations, allocation of the VUF based on the unbalanced component (MVA rating) of the installation instead of its entire agreed power would be reasonable. This enables the system operator to provide an increased VUF emission limits to other unbalanced installations connected to the same network, while maintaining the net VU of the network within the network planning levels. Thus, the VU allocation in (6) for an installation can be modified as (8),

$$
E_{V U F: i}=k \cdot \sqrt[\alpha]{U_{f} \cdot S_{i}}
$$

where $U_{f}$ is the ratio of MVA capacity of the unbalanced component $\left(S_{i \text { :unbalanced }}\right)$ of the installation to the agreed power of the installation $\left(S_{i}\right)$ (i.e. $\left.U_{f}=S_{i \text { :unbalanced }} / S_{i}\right)$.

Assume that that installation L3 connected to the distribution network given in Fig. 2 to be fully balanced $\left(U_{f}=1.0\right)$ and MVA capacity of the unbalanced component of installation $\mathrm{L} 1$, installation L4 and installation L5 are equal to 0.5 . The 
VU emission allocation limits for each installation in the distribution network of Fig. 2, when an allocation is made based on unbalanced MVA capacity of each installations are given in Table II.

As expected, the VU emission limits for installations L2 and L6 have increased to $0.53 \%$ and $0.28 \%$ respectively, compared to $0.37 \%$ and $0.19 \%$ in Case $I$.

\section{The Impact of Single-phase/Two-phase Installations}

The proposed methodology can be modified to estimate the VU emission limits for unbalanced installations connected to a distribution network in situations where there is a special installation such as a single or two-phase installation connected to the same network. For a single or two-phase installation the $\mathrm{VU}$ emission is given by (9)

$$
E_{V U F: i}=\frac{S_{i}}{S_{s c: i}} \cdot C U F_{i}
$$

where;

$E_{V U F: i}$ is the magnitude of VUF at the $i^{\text {th }}$ busbar where the load is connected

$C U F_{i}$ is the magnitude of current unbalance factor (CUF) of the installation

$S_{i}$ is MVA capacity of the single or two-phase installation $S_{s c: i}$ is the short-circuit level at the $i^{\text {th }}$ busbar

The CUF for different configurations of single and twophase installations are given in Table. III [8].

TABLE III

CURRENT UNBALANCE FACTOR FOR DIFFERENT CONFIGURATIONS OF SINGLE AND TWO-PHASE INSTALLATIONS

\begin{tabular}{|c|c|}
\hline Configuration & $\left|C U F_{i}\right|$ \\
\hline 1-phase connection with neutral & 1 \\
\hline 2-phase connection with neutral & 0.5 \\
\hline 1-phase connection without neutral & 1 \\
\hline 2-phase connection without neutral & 0.5 \\
\hline
\end{tabular}

To illustrate the application of proposed methodology in the presence of single or two-phase installations the distribution network in Fig. 2 was modified by replacing the 3.5 MVA installation with a single-phase installation (without neutral connection) with an MVA capacity of 0.5 MVA. The VU emission from the single-phase installation was determined as $0.5586 \%$ using (9). Allocation of VU for the remaining three-phase installations can be made using (6) while the VU emission limit for the single phase load is replaced by its VUF emission calculated previously using (9). Following the proposed methodology in Section III-A and (3), the allocation constant for the network is calculated as 0.0034 . The resulting VU emission limits for three-phase installations are tabulated in Table IV.

TABLE IV

EMISSION ALLOCATION FOR EACH THREE-PHASE INSTALLATION $\left(k=0.0034, S_{\text {base }}=10 \mathrm{MVA}\right)$

\begin{tabular}{|c|c|c|c|}
\hline Bus ID & $\begin{array}{l}\text { Installation capacity } \\
\text { connected to the bus }\end{array}$ & $\begin{array}{l}\text { Total VUF at } \\
\text { the busbar }(\%)\end{array}$ & $\begin{array}{l}\text { Allocated VUF to } \\
\text { the installation (\%) }\end{array}$ \\
\hline MV & & 1.5442 & \\
\hline $\mathbf{A}$ & $2.0 \mathrm{MVA}$ & 1.5600 & 0.1121 \\
\hline B & 5.0 MVA & 1.6461 & 0.2158 \\
\hline C & $\begin{array}{l}0.5 \text { MVA single- } \\
\text { phase installation }\end{array}$ & 1.7500 & - \\
\hline D & $2.5 \mathrm{MVA}$ & 1.5874 & 0.1316 \\
\hline $\mathbf{E}$ & 5.0 MVA & 1.6116 & 0.2158 \\
\hline $\mathbf{F}$ & 2.0 MVA & 1.6000 & 0.1121 \\
\hline
\end{tabular}

If there is more than one single or two-phase installation connected to the network across different phases, the application of general summation law can lead to conservative results, hence, the specific characteristics of the connection scheme should be taken into account.

\section{ANALYSIS OF THE IMPACT OF INDUCTION MOTOR INSTALLATIONS}

The presence of an induction motor installation on a radial network can improve the VU levels in the same network [9]. An influence factor $(\beta)$ which is defined as (10) has been introduced in [10], to quantify the VU attenuation provided by the induction motors. Considering a single unbalanced installation and inductor motor installation, a methodology to evaluate $\beta$ is provided in [10].

$$
\beta=\frac{V U F_{\mathrm{L}} \text { with the induction motor load }}{V U F_{\mathrm{L}} \text { without induction motor load }}
$$

where $V U F_{L}$ is the VU level at the PCC of the installation.

To illustrate the application of the concept of the influence factor for VU emission allocation, consider the radial distribution network given in Fig. 2. The network is modified by connecting $2.3 \mathrm{kV} / 2250 \mathrm{HP}$ induction motor installation through $12.47 / 2.3 \mathrm{kV}$ motor servicing transformer at busbar A. Influence factors are estimated using the methodology given in [10] and the resulting values are given in Table V. The impedance of the motor servicing transformer and equivalent circuit parameters of the induction motor are given in Appendix B.

TABLE V

INFLUENCE FACTORS

\begin{tabular}{|c|c|}
\hline Installation ID & $\beta$ \\
\hline L1 & 0.9136 \\
L2 & 0.9689 \\
L3 & 0.9790 \\
L4 & 0.9689 \\
L5 & 0.9775 \\
L6 & 0.9803 \\
\hline
\end{tabular}

Referring to Table V, the highest attenuation of VU can be observed when induction motor load and an unbalanced installation is connected to the same PCC.

Due to the VU attenuation provided by induction motor loads, the net VU absorption capacity of the networks has now increased. This additional VU absorption capacity could be used to allocate for other unbalanced installation connected to the same network by modifying the VU emission allocation equation given in (8) to give (11)

$$
E_{V U F: i-\text { effective }}=\beta \cdot E_{V U F: i}
$$

where $E_{V U F: i-\text { effective }}$ is the effective VUF emission from the unbalanced installation considering the attenuation provided by the induction motor installation, $\beta$ is the influence factor, and $E_{V U F: i}$ is the VU emission limit for the installation and equals $k \cdot \sqrt[\alpha]{S_{i}}$. Substituting $E_{V U F: i}$ in (3)-(5) with $E_{V U F: i-\text { effective, the allocation constant can be determined }}$ subject to the condition specified in Section III-A.

A comparison of the resulting VU emission limits for an unbalanced installation without and with considering the attenuation of induction motor installations are given in Fig. 3. All installations were considered to be totally unbalanced $\left(U_{f}=1\right)$. However, no allocation was made to the induction motor installation. As expected, the allocation limits have sightly increased latter case, compared to the former. 


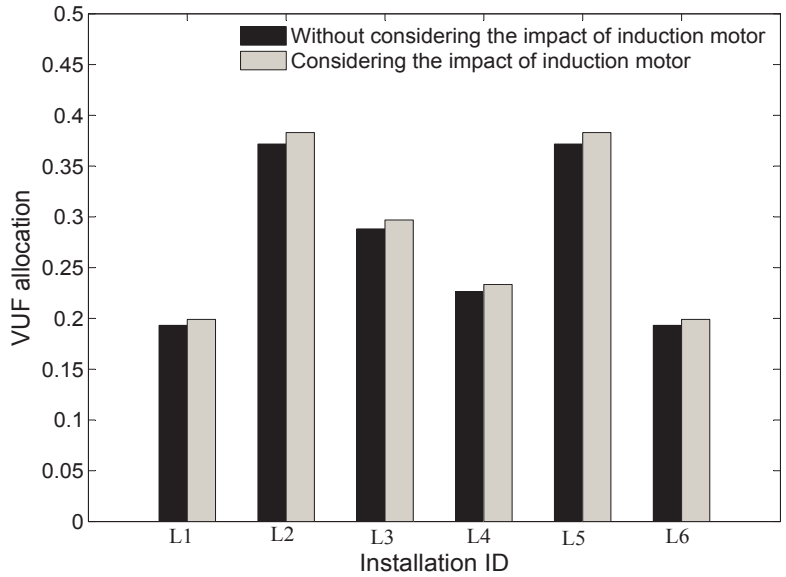

Fig. 3. Impact of induction motor loads on the VU emission allocation

\section{CONCLUSION}

A revised methodology for $\mathrm{VU}$ allocation based on the $\mathrm{CBV}$ methodology in radial distribution networks is presented in this paper. The proposed methodology provides a robust and flexible approach for VU allocation, which can accommodate constraints such as the presence of single and two-phase installations. The impact of induction motor installations on the VU allocation process is also investigated in the paper. The main difficulty with the proposed methodology is that the fault level at the PCC and the MVA capacities of each installation are required to be known in advance. However, such difficulties can be overcome by intuitive, good engineering judgment and planning. Furthermore, with appropriate adjustments the proposed methodology can be easily used for stage three emission allocation process to supplement the IEC emission allocation process.

\section{APPENDIX A}

\section{DERIVATION OF EQUATION (1)}

Considering a radial distribution network given in Fig. 1 in Section II and assuming that only load $i$ is operating, VUF at the $i^{\text {th }}$ busbar $\left(V U F_{i}\right)$ and $\mathrm{MV}$ busbar $\left(V U F_{\mathrm{MV}}\right)$ can be given by (A.1) and (A.2) respectively.

$$
\begin{gathered}
V U F_{\mathrm{i}}=\left|-\left(\frac{Z_{11: \mathrm{tr}}+Z_{11: \text { line }}}{Z_{11 \text { load }}}\right)\right| \cdot C U F_{\text {load }} \\
V U F_{\mathrm{MV}}=\left|-\left(\frac{Z_{11: \mathrm{tr}}}{Z_{11: \text { load }}}\right) \cdot \frac{U_{1: \mathrm{i}}}{U_{1: \mathrm{MV}}}\right| \cdot C U F_{\text {load }}
\end{gathered}
$$

where $Z_{11 \text { :tr }}, Z_{11 \text { :line }}, Z_{11 \text { :load }}, C U F_{\text {load }}$ are the positivesequence impedance of the transformer, positive-sequence impedance of distribution line from MV busbar to the $i^{\text {th }}$ busbar, positive-sequence impedance the load and the magnitude of current unbalance factor of the load connected to $i^{\text {th }}$ busbar respectively. $U_{1: \mathrm{MV}}$ and $U_{1: i}$ stand for the positive-sequence voltage at the MV busbar and positive-sequence voltage at the intermediate busbar $i$ respectively.

Hence, the VUF transfer coefficient from $i^{\text {th }}$ busbar to MV busbar $T_{u: i-\mathrm{MV}}\left(V U F_{\mathrm{MV}} / V U F_{i}\right)$, can be established as given by (A.3),

$$
T_{u: i-\mathrm{MV}}=\left|\frac{Z_{11: \mathrm{tr}} \cdot C U F_{\mathrm{load}}}{\left(Z_{11: \mathrm{tr}}+Z_{11: \mathrm{line})} \cdot C U F_{\mathrm{load}}\right.} \cdot \frac{U_{1: \mathrm{i}}}{U_{1: \mathrm{MV}}}\right|
$$

Assuming that $U_{1: \mathrm{MV}} \approx U_{1: i}, T_{u: i-\mathrm{MV}}$ can be expressed as (A.4),

$$
T_{u: i-\mathrm{MV}} \approx\left|\frac{Z_{11: \operatorname{tr}}}{Z_{11: \mathrm{tr}}+Z_{11: \text { line }}}\right|
$$

Equation (A.4) can be further simplified to (A.5) where $S_{s c: \mathrm{MV}}$ short-circuit capacity of the MV busbar and $S_{s c: i}$ is the short-circuit capacity of the $i^{\text {th }}$ busbar.

$$
T_{u: i-\mathrm{MV}} \approx\left|\frac{S_{s c: i}}{S_{s c: \mathrm{MV}}}\right|
$$

Equation (A.5) implies that when only one installation is operating at a time, the VU transfer coefficient from the PCC of the considered installation to an upstream point of the network can be approximated by the ratio of short-circuit level of two locations. The reader should note due to the assumption $U_{1: \mathrm{MV}} \approx U_{1: i}$, (A.5) provides a slight over-estimation of $\mathrm{VU}$ propagation [10] from $i^{\text {th }}$ busbar to MV busbar.

\section{APPENDIX B}

\section{NETWORK DATA}

The network parameter of the MV distribution network in Section III-B.

Line parameters: The phase impedance matrix of the $12.47 \mathrm{kV}$ distribution line sections in Section III-B in $\Omega / \mathrm{km}$

$\left[\begin{array}{ccc}0.2494+j 0.8748 & 0.0592+j 0.4811 & 0.0592+j 0.4811 \\ 0.0592+j 0.4811 & 0.2494+j 0.8748 & 0.0592+j 0.4811 \\ 0.0592+j 0.4811 & 0.0592+j 0.4811 & 0.2494+j 0.8748\end{array}\right]$

Transformer parameters:

138/12.47kV transformer: $20 \mathrm{MVA}, 60 \mathrm{~Hz}, 0.0048+\mathrm{j} 0.09988 \mathrm{pu}$ impedance

12.47/2.3 kV transformer: 5 MVA, $60 \mathrm{~Hz}, 0.01+\mathrm{j} 0.07937 \mathrm{pu}$ impedance

Induction motor parameters:

$2.3 \mathrm{kV}, 2250 \mathrm{HP}, 60 \mathrm{~Hz}, r_{s}=0.0269 \Omega, X_{l s}=0.226 \Omega, X_{M}=$ $13.04 \Omega, X_{l r}^{\prime}=0.226 \Omega, R_{r}^{\prime}=0.022 \Omega$ and $J=63.87 \mathrm{~kg} . \mathrm{m}^{2}$

\section{REFERENCES}

[1] P. Paranavithana, "Contributions Towards the Development of the Technical Report IEC/TR 61000-3-13 on Voltage Unbalance Emission Allocation," Ph.D. dissertation, School of Electrical, Computer and Telecommunications Engineering, University of Wollongong, Australia, March 2009.

[2] "Electromagnetic compatibility (EMC) - limits - assessment of emission limits for the connection of unbalanced installations to MV, HV and EHV power systems," Technical report IEC/TR 61000-3-13, Ed. 1, International Electrotechnical Commission, 2008.

[3] "Electromagnetic compatibility (EMC) - limits - assessment of emission limits for distorting loads in MV and HV power systems," Technical report IEC/TR 61000-3-6, Ed. 1, International Electrotechnical Commission, 1996

[4] "Electromagnetic compatibility (EMC) - limits - assessment of emission limits for fluctuating loads in MV and HV power systems," Technical report IEC/TR 61000-3-7, Ed.1,International Electrotechnical Commission, 1996

[5] "Technical Rules for the Assessment of Network Disturbances", 2nd Edition, 2007.

[6] T.J. Browne, "Harmonic management in transmission networks," Ph.D dissertation, School of Electrical, Computer and Telecommunications Engineering, University of Wollongong, Australia, March 2008.

[7] "Electromagnetic compatibility (EMC) - Parts 2-2: Environment - Compatibility levels for low-frequency conducted disturbances and signaling in public low-voltage power supply systems," IEC 61000-2-2, Ed. 2.0, in public low-voltage power supply systems," IEC 61000-2-2, Ed. 2.0, 2002

[8] "Review of disturbance emission assessment techniques," CIGRE/CIRED C4.109 WG Report 468, June 2011.

[9] U. Jayatunga, S. Perera and P. Ciufo, "Voltage Unbalance Emission Assessment in Radial Power Systems," IEEE Trans. Power Del, vol.27, no.3, pp.1653-1661, Jul. 2012.

[10] D. Perera, P. Ciufo, S. Perera and L. Meegahapola, "Attenuation and Propagation of Voltage Unbalance in Radial Distribution Networks," unpublished, Available: http://works.bepress.com/pciufo/32/ 